Gut, 1979, 20, 305-308

\title{
Nippostrongylus brasiliensis infection in the rat: effect of iron and protein deficiency on the anthelmintic efficacy of mebendazole, pyrantel, piperazine, and levamisole
}

\author{
V. M. DUNCOMBE ${ }^{1}$, T. D. BOLIN, A. E. DAVIS, M. R. FAGAN, AND \\ J. D. KELLY
}

From the University of New South Wales, Gastrointestinal Unit, Prince of Wales Hospital, Randwick, and Department of Veterinary Pathology, University of Sydney, New South Wales, Australia

SUMMARY The benzimidazole anthelmintics mebendazole and fenbendazole have been shown to be much less effective against Nippostrongylus brasiliensis infections in the rat on a combined iron and protein deficient diet. In the present experiments it was shown that the anthelmintic efficacy of mebendazole was significantly impaired in the rat on either an iron deficient or a protein deficient diet. Furthermore, iron and protein deficiency reduced the efficacy of the anthelmintics pyrantel and piperazine but not levamisole. The finding that nutritional deficiencies reduce anthelmintic efficacy may well be relevant to worm eradication programmes in iron deficient and protein calorie malnourished populations.

Malnutrition is a major problem in developing countries and is certain to increase if present population trends continue to exceed rises in food production (Knowles, 1972). Infectious disease is being recognised as an important contributing factor to malnutrition (Mata et al., 1977) and gastrointestinal infections in particular play a major role by inducing anorexia, diarrhoea, steatorrhoea, and a negative nitrogen balance (Scrimshaw et al., 1968). In addition, it is common in many societies to restrict dietary intake in children with diarrhoea, thus further exacerbating malnutrition.

It therefore seems likely that control of gastrointestinal infections will improve the nutritional status of individuals on a marginal diet. Programmes aimed at eradication of gut parasites, however, have often met with limited success (Best et al., 1976). One reason for this may be that some drugs are less effective in malnourished individuals, as it has been shown that the anthelmintic efficacy of mebendazole and fenbendazole is decreased in combined iron and protein deficiency states (Dun-

'Present address: Department of Medicine, Royal Postgraduate Medical School, Ducane Road, London W.12. Received for publication 11 October 1978 combe et al., 1977). As iron deficiency alone is common and as this effect may be specific to the benzimidazole anthelmintics mebendazole and fenbendazole, it was relevant to examine the effect of separate deficiencies of iron and protein on anthelmintic efficacy as well as the efficacy of several chemically unrelated anthelmintics in nutritional deficiency states. For this purpose the Nippostrongylus brasiliensis/rat model was used.

$N$. brasiliensis is a nematode with a life cycle similar to that of many helminths of medical and veterinary importance. Infective larvae penetrate the skin and proceed via the blood stream and lymphatics to the lungs. Larvae then migrate up the trachea and down the oesophagus to the small intestine, where they mature into adult worms, and begin egg production. Infected animals then mount a complex immune response which results in the elimination of the majority of worms between days 10-16 of infection (Kelly and Dineen, 1972).

\section{Methods}

PREPARATION AND ADMINISTRATION OF INFECTIVE LARVAE

Third stage larvae of $N$. brasiliensis were obtained from faeces-charcoal cultures, filtered through 
Table 1 Mean haemoglobin and albumin estimations and body weight of iron and protein deficient and sufficient rats

\begin{tabular}{|c|c|c|c|c|}
\hline \multirow[t]{2}{*}{ Dietary status } & \multicolumn{2}{|l|}{ Deficient } & \multirow[t]{2}{*}{ Sufficient (mean $\pm S E$ ) } & \multirow[t]{2}{*}{$\mathbf{P}$ value $(* v s \dagger)$} \\
\hline & Iron $(m e a n \pm S E)$ & Protein $($ mean $\pm S E)$ & & \\
\hline $\begin{array}{l}\text { Haemoglobin }(\mathrm{g} / \mathrm{dl}) \\
\text { Weight }(\mathrm{g}) \\
\text { Albumin }(\mathrm{g} / \mathrm{l})\end{array}$ & $\begin{array}{c}7 \cdot 5 \pm 0 \cdot 6^{*} \\
265 \pm 2 \cdot 9^{*} \\
29 \pm 0 \cdot 2^{*}\end{array}$ & $\begin{aligned} 13 \cdot 2 & \pm 0 \cdot 3 \dagger \\
124 & \pm 5 \cdot 1 \dagger \\
25 & \pm 0 \cdot 3 \dagger\end{aligned}$ & $\begin{aligned} 15 \cdot 0 & \pm 0 \cdot 4 \dagger \\
257 & \pm 7 \cdot 2^{*} \\
30 & \pm 0 \cdot 2^{*}\end{aligned}$ & $\begin{array}{l}<0.01 \\
<0.01 \\
<0.01\end{array}$ \\
\hline
\end{tabular}

Table 2 Effect of iron deficiency and protein deficiency on efficacy of mebendazole in rats infected with Nippostrongylus brasiliensis

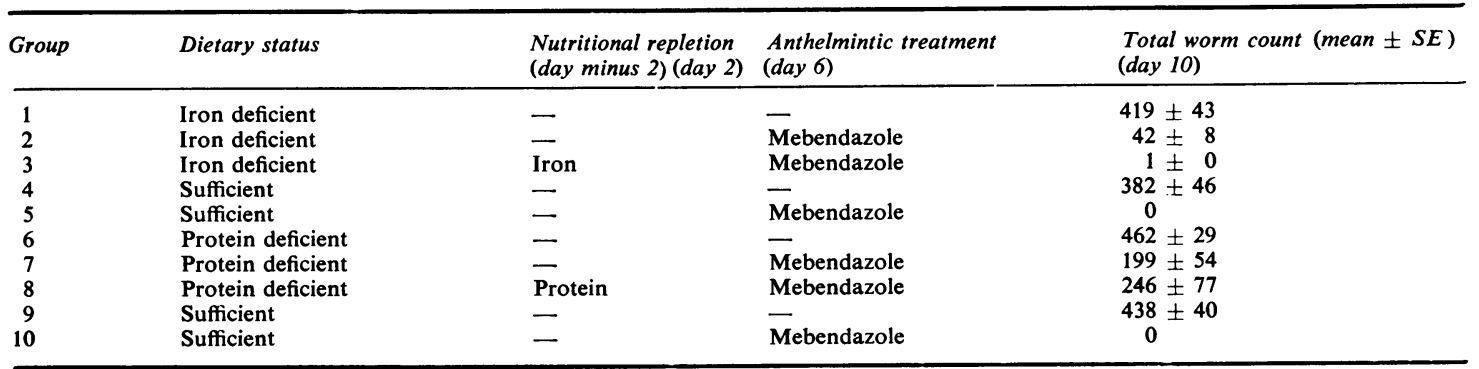

surgical gauze, washed in normal saline, and then counted. Rats were infected by subcutaneous inoculation in the abdominal region (Kelly and Dineen, 1972).

\section{PREPARATION OF DIETS}

Diets were prepared using $30 \%$ protein (as calcium caseinate), $50 \%$ carbohydrate, and $9.6 \%$ fat with vitamin and mineral supplements. Iron was withdrawn from the mineral supplements in iron deficient diets and, in addition, the rats were housed in brass cages and given distilled drinking water. The casein content of protein deficient diets was reduced from $30 \%$ to $10 \%$ and the diet made isocaloric by increasing the carbohydrate content appropriately (Bolin et al., 1971).

\section{ANTHELMINTICS}

Mebendazole (methyl-5(6)-benzoyle 1-2 benzimidazole carbamate)-Telmin, Ethnor Pty. Ltd, North Ryde, New South Wales, Australia, levamisole (1 (-) 2,3,5,6-tetrahydro-6-phenylimidazo (2, 1-b) thiazole)-Nilverm, I.C.I. Aust. Ltd, Melbourne, Victoria, Australia, Pyrantel (1,4,5,6-tetrahydro-1methyl-2- (trans 2- (2-thiaenyl) -vinyl-primidine ebonate) Combantrin, G.P. Laboratories, West Ryde, New South Wales, Australia, and piperazine citrate (hexahydropyrazine) Antepar, Wellcome (Australasia) Pty. Ltd, Rosebery, New South Wales, Australia were obtained commercially. Dose rates used were determined from a pilot study and were; mebendazole $12.5 \mathrm{mg} / \mathrm{kg}$; levamisole $7 \mathrm{mg} / \mathrm{kg}$; pyrantel $10 \mathrm{mg} / \mathrm{kg}$; and piperazine $400 \mathrm{mg} / \mathrm{kg}$.

\section{STATISTICS}

Haemoglobin, weight, and albumin data were analysed by Student's $t$ test. Analysis of variance was carried out on all worm count data after transformation to $\log _{10}(x+1)$.

\section{Experimental design and results}

EFFECT OF SEPARATE DEFICIENCIES OF IRON AND PROTEIN ON ANTHELMINTIC EFFICACY OF MEBENDAZOLE

Fifty Wistar rats were divided into 10 groups of five animals and weaned onto synthetic diets at 4 weeks of age. Three of these groups were fed an iron deficient diet (groups 1-3), three groups were fed a protein deficient diet (groups 6-8), and four groups were fed a diet sufficient in both iron and protein (groups 4, 5, 9, and 10). After six weeks on the diet, all rats were weighed and blood collected for haemoglobin estimations. Albumin levels were determined at time of necropsy. These results, which are presented in Table 1 , confirm that rats on the iron deficient diet were anaemic, while those on the protein deficient diet were underweight and had low serum albumin levels.

Two groups, one iron deficient (group 3) and one protein deficient (group 8), were repleted by reverting to an iron or protein sufficient diet two days before inoculation with larvae of $N$. brasiliensis. In addition, rats in the iron replenished group were treated with $5 \mathrm{mg}$ iron dextran (Imferon, Fisons Pty. Ltd, North Sydney, Australia) by intramuscular injection. 
At 10 weeks of age animals were inoculated with 1000 larvae of $N$. brasiliensis. Six days after infection one iron deficient group (group 2) and one protein deficient group (group 7), both replenished groups (groups 3 and 8), and two of the sufficient groups (5 and 10) were treated with mebendazole by intragastric intubation at a dose rate of $12.5 \mathrm{mg} / \mathrm{kg}$.

Four days later, on day 10 of infection, all animals were submitted to necropsy to assess total worm counts and these results are shown in Table 2. The mean worm counts in all untreated groups were not significantly different, regardless of dietary status (groups 1, 4, 6, 9, mean worm counts 419, 382,462 , and 438 respectively).

The mean worm count in the mebendazole treated iron deficient rats (group 2) was 42. In contrast, in iron sufficient rats treated with mebendazole (group 5) the parasites were completely eradicated, the mean worm count being 0 . Thus mebendazole was significantly less effective in iron deficient rats (group 2 versus group 5; $\mathrm{P}<0.01$ ). This lowered anthelmintic efficacy in iron deficient rats could be overcome by iron repletion two days before infection, the mean worm count for iron repleted animals (group 3 ) being only one (group $3 \mathrm{vs.}$ group 5; P > 0.05).

The mean worm count for mebendazole treated protein deficient rats (group 7) was 199, indicating a significant decrease in anthelmintic efficacy when compared with rats on a sufficient diet (group 10, mean worm count 0 ; group 7 vs. group $10 ; P<0.01$ ). Unlike repletion in iron deficient rats, protein repletion did not improve anthelmintic efficacy, the mean worm count for repleted animals (group 8) being 246 (group 7 vs. group 8; P > 0.05).

\section{EFFECT OF COMBINED IRON AND PROTEIN DEFICIENCY ON ANTHELMINTIC EFFICACY OF LEVAMISOLE, PYRANTEL, AND PIPERAZINE}

At 4 weeks of age four groups each of five Wistar rats were weaned onto a synthetic diet and three groups of five rats were weaned onto a combined iron and protein deficient diet. Six weeks later all animals were weighed and blood collected for haemoglobin and albumin estimations as with the previous experiment. The results (Table 3 ) confirmed that rats on an iron and protein deficient diet were under-weight, anaemic, and had low serum albumin levels.

All animals were then inoculated with 1000 larvae of $N$. brasiliensis. On day six of infection rats in groups 2 and 3 were tested with levamisole, groups 4 and 5 with pyrantel, and 6 and 7 with piperazine. Animals in group 1 were left untreated and served as infection controls.
Table 3 Mean haemoglobin and albumin estimations and body weight of iron and protein deficient and sufficient rats

\begin{tabular}{|c|c|c|c|}
\hline \multirow[t]{2}{*}{ Dietary status } & \multicolumn{2}{|c|}{ Iron and protein } & \multirow[t]{2}{*}{ P value } \\
\hline & $\begin{array}{l}\text { Deficient } \\
(\text { mean } \pm S E)\end{array}$ & $\begin{array}{l}\text { Sufficient } \\
(\text { mean } \pm S E)\end{array}$ & \\
\hline $\begin{array}{l}\text { Haemoglobin } \\
(\mathrm{g} / \mathrm{dl})\end{array}$ & $8.9 \pm 0.4$ & $13.6 \pm 0.3$ & $<0.01$ \\
\hline $\begin{array}{l}\text { Weight (g) } \\
\text { Albumin (g/l) }\end{array}$ & $\begin{aligned} 111 & \pm 5 \\
25 & \pm 0.02\end{aligned}$ & $\begin{aligned} 197 & \pm 5 \\
29 & \pm 0.03\end{aligned}$ & $\begin{array}{l}<0.01 \\
<0.01\end{array}$ \\
\hline
\end{tabular}

Table 4 Effect of iron and protein deficiency on efficacy of pyrantel, piperazine, and levamisole in rats infected with Nippostrongylus brasiliensis

\begin{tabular}{|c|c|c|c|c|}
\hline Group & $\begin{array}{l}\text { Dietary } \\
\text { status }\end{array}$ & $\begin{array}{l}\text { Treatment } \\
\text { (day 6) }\end{array}$ & $\begin{array}{l}\text { Dose } \\
(m g / k g)\end{array}$ & $\begin{array}{l}\text { Total worm count } \\
\text { (mean } \pm S E) \\
\text { (day) } 10\end{array}$ \\
\hline 1 & Sufficient & Nil & - & $400 \pm 25$ \\
\hline 2 & Sufficient & Levamisole & 7 & 0 \\
\hline 3 & Deficient & Levamisole & 7 & 0 \\
\hline 4 & Sufficient & Pyrantel & 10 & $0.8 \pm 0$ \\
\hline 5 & Deficient & Pyrantel & 10 & $159 \pm 22$ \\
\hline 6 & Sufficient & Piperazine & 400 & $10 \pm 6$ \\
\hline 7 & Deficient & Piperazine & 400 & $368 \pm 63$ \\
\hline
\end{tabular}

Four days later on day 10 of infection all rats were necropsied for total worm counts, and these results are presented in Table 4. The mean count for untreated rats is 400 (group 1). Levamisole at a dose rate of $7 \mathrm{mg} / \mathrm{kg}$ was fully effective in eradicating $N$. brasiliensis in both sufficient (group 2, mean worm count 0 ) and deficient (group 3, worm count 0 ) rats. In contrast pyrantel was effective in iron and protein sufficient rats (group 4, mean worm count 0.8 ) but much less effective in iron and protein deficient rats (group 5, mean worm count 159). Similarly, piperazine was less effective in deficient rats (group 7, mean worm count 368) than in sufficient rats (group 6, mean worm count 10). The difference in anthelmintic efficacy between sufficient and deficient animals was significant at the $1 \%$ level for both pyrantel and piperazine but not for levamisole.

\section{Discussion}

The results of this study show that mebendazole is a much less effective anthelmintic in rats which are either iron deficient or protein deficient. This is particularly significant in the case of iron deficiency, not only because of the prevalence of iron deficiency but also because of the association of iron deficiency with helminth infections such as hookworm.

It was also important that iron therapy two days before parasite infection fully restored the efficacy 
of mebendazole in iron deficient rats. It was perhaps not surprising that the same effect was not seen in the protein deficient groups, as protein deficient rats become anorexic and a longer period of supplementation may well be necessary to overcome the effects of protein depletion.

The present studies also demonstrated that pyrantel and piperazine but not levamisole have reduced efficacy in iron and protein deficiency states. This difference remains unexplained, as does the mechanism by which anthelmintic efficacy was reduced in iron and protein deficiency. Studies are in progress to examine the effect of nutritional deficiencies on the pharmacokinetics of these anthelmintics, as a reduced serum half life of some drugs has been demonstrated in malnourished subjects and this effect may occur with anthelmintics. An alternative explanation may be that anthelmintics act in concert with the immune response to effect worm expulsion, resulting in lowered efficacy in immunodeficiency states. It is of interest in regard to this hypothesis that levamisole, the only tested anthelmintic to remain unaffected by iron and protein deficiency, has the capacity to stimulate the immune response (Renoux and Renoux, 1972; Tripodi et al., 1973).

There have been no controlled studies in man comparing anthelmintic efficacy in malnourished and well-nourished populations. However, Scragg and Proctor (1977) have observed that a course of mebendazole achieved a complete cure in only $43 \%$ of malnourished children with symptomatic Trichuris trichuria. This contrasts with reports of $80-95 \%$ cure rate for trichuris with mebendazole (Peña Chavarria et al., 1973; Hutchison et al. 1975), but unfortunately there is no assessment of nutritional status reported in these latter studies.

If the results of these studies on anthelmintic efficacy can be extrapolated to man, they have obvious therapeutic implications. In malnourished populations extended courses of anthelmintic drugs with increased dosage schedules should be given rather than low dose rates as practised by some workers to reduce side-effects. Where possible, anthelmintic programmes should be integrated with nutritional supplementation or timed to coincide with age or time of season when nutritional status is optimal. In iron deficient populations iron therapy before anthelmintic treatment may be feasible and effective.

Finally, more research and a greater awareness of the effect of nutritional deficiencies on drug action is needed, as malnutrition is common not only in the developing countries but is also widespread in hospital patients in Western society (Bistrian et al., 1974; Hill et al., 1977).

This study was supported by a grant from the National Health and Medical Research Council of Australia. The authors would like to acknowledge with thanks the expert assistance of $\mathrm{Mr} \mathrm{C}$. Porter, Mr D. Griffin, and Mrs I. MacLean.

\section{References}

Best, J. C., Welch, J. S., Filippich, C., and McPhee, L. (1976). Treatment of intestinal parasites in Australian Aboriginal children. Medical Journal of Australia, 1, 14-20.

Bistrian, R. B., Blackburn, G. L., Hallowell, E., and Heddle, R. (1974). Protein status of general surgical patients. Journal of the American Medical Association, 230, 858-860.

Bolin, T. D., McKern, A., and Davis, A. E. (1971). The effect of diet on lactase activity in the rat. Gastroenterology, 60, 432-437.

Duncombe, V. M., Bolin, T. D., Davis, A. E., and Kelly, J. D. (1977). Nippostrongylus brasiliensis infection in the rat: effect of iron and protein deficiency and dexamethasone on the efficacy of benzimidazole anthelmintics. Gut, 18, 892-896.

Hill, G. L., Blackett, R. L., Pickford, I., Burkinshaw, L., Young, G. A., Warren, J. V., Schorah, C. J., and Morgan, D. B. (1977). Malnutrition in surgical patients. An unrecognised problem. Lancet, 1, 689-692.

Hutchison, J. G. P., Johnston, N. M., Plevey, M. V. P., Thangkhiew, I. O., and Aidney, C. (1975). Clinical trial of mebendazole, a broad-spectrum anthelminthic. British Medical Journal, 2, 309-310.

Kelly, J. D., and Dineen, J. K. (1972). The cellular transfer of immunity to Nippostrongylus brasiliensis in inbred rats (Lewis strain). Immunology, 22, 199-210.

Knowles, J. H. (1976). American medicine and world health (Editorial). Annals of Internal Medicine, 84, 483-485.

Mata, L. J., Kromal, R. A., Urrutia, J. J., and Garcia, B. (1977). Effect of infection on food intake and the nutritional state: perspectives as viewed from the village. American Journal of Clinical Nutrition, 30, 1215-1227.

Peña Chavarría, A., Swartzwelder, J. C., Villarejos, V. M., and Zeledón, R. (1973). Mebendazole, an effective broad spectrum anthelmintic. American Journal of Tropical Medicine and Hygiene, 22, 592-595.

Renoux, G., and Renoux, M. (1972). Antigenic competition and nonspecific immunity after a Rickettsial infection in mice: restoration of antibacterial immunity by phenylimidothiazole treatment. Journal of Immunology, 109, 761-765.

Scragg, J. N., and Proctor, E. M. (1977). Mebendazole in the treatment of severe symptomatic trichuriasis in children. American Journal of Tropical Medicine and Hygiene, 26, 198-203.

Scrimshaw, N. S., Taylor, C. E., and Gordon, J. E. (1968). Interactions of nutrition and infection. WHO Monograph Series, 57.

Tripodi, D., Parks, L. C., and Brugmans, J. (1973). Druginduced restoration of cutaneous delayed hypersensitivity in anergic patients with cancer. New England Journal of Medicine, 289, 354-357. 